\title{
Effects of story mapping on third-grade students with Attention Deficit Hyperactivity Disorder
}

Jaime N. Chavez, Ed. S., James Martinez, Rachel S. Pienta

Abstract: The purpose of this study was to examine the effects of story mapping on the reading comprehension scores, on-task behaviors, and attitudes of third-grade students $(N=6)$ with ADHD. Students' reading grade equivalencies were assessed before and after the study. The teacher-researcher compared two other achievement measures before and during story mapping to assess growth. The practical difference in scores as calculated with Cohen's $d$ revealed that story mapping was successful in improving students' comprehension. On tests from the reading basal, students' scores improved an average of $16.00 \%$, while tests from a computerized reading program improved $20.00 \%$. Students exhibited on-task behavior $79.33 \%$ of the time and positive attitudes $82.33 \%$ of the time during the intervention. The implications of this study are important in determining effective instructional strategies to promote the active engagement of students and combat the core symptoms of ADHD.

Key words: reading comprehension, story mapping, special education, special education, Attention Deficit Hyperactivity Disorder.

\section{Effects of Story Mapping on Third-Grade Students with Attention Deficit Hyperactivity Disorder}

A child's future success, including earning potential and the ability to contribute to the nation's economy, is based on the ability to read. According to research conducted by The Annie E. Casey Foundation (2010), "two 
out of every three fourth graders overall are not proficient in reading" (para. 1). In order for children who are at risk for reading failure to have long term success, they must receive intensive and systematic reading instruction prior to third grade (Lyon, 1999). Lyon (1999) reported that $75 \%$ of students who do not receive this type of reading instruction continue to have significant reading difficulties as an adult.

In order to address gaps in achievement among the nation's schools, the No Child Left Behind Act (NCLB) was established in 2001. Each state developed benchmark assessments in order to measure progress and ensure that all students are learning. In Georgia public schools, all third-grade students enrolled in regular education classrooms must pass the Reading section of the Criterion Referenced Competency Test (CRCT) in order to be promoted to fourth grade. Students are expected to read text passages from various genres and answer questions related to the text. In order to be successful, students must be equipped with reading strategies that will enable them to score well on the test. Aside from high-stakes testing, reading is an imperative life skill that will assist students in being successful across the curriculum.

\section{Justification and Benefits of Research}

Unfortunately, many students move through school reading below grade level. According to Lesnick, Goerge, Smithgall, and Gwynne (2010), "Students who are not reading at grade level by third grade begin having difficulty comprehending the written material that is a central part of the educational process in the grades that follow" (p. 1). For this reason, teachers must equip students with strategies that will enable them to not only decode words and understand vocabulary but also comprehend the text they are reading. These strategies must be taught through explicit instruction aimed at creating proficient readers who can transfer these strategies to various genres and subject areas. In sum, Stagliano and Boon (2009) stated, "Comprehension is critically important to the development of children's reading skills and therefore to the ability to obtain an education" (p. 36).

\section{Deficits in Reading Proficiency}

National data

In a study released in April 2011, the American Educational Research Association reported that students who do not read proficiently by third 
grade are 4 times less likely to graduate than proficient readers (Hernandez, 2011). These statistics apply to one in six children. The dropout rate is highest for the low, below-basic readers. Hernandez (2011) stated that "23 percent of these children drop out or fail to finish high school on time, compared to 9 percent of children with basic reading skills and 4 percent of proficient readers" (p. 2). Daggett and Hasselbring (2007) reported that "lack of reading proficiency undermines self-image and self-confidence throughout life," and those who have difficulty reading are not generally engaged in learning (p. 4).

The academic success of a child is often dependent on the ability to remain on task in the classroom with minimal distraction (U.S. Department of Education, 2004). Students with Attention Deficit Hyperactivity Disorder (ADHD) often have difficulty sustaining attention to tasks, organizing thoughts and materials, and listening to and following directions. In 2010, the Centers for Disease Control and Prevention (CDC) reported that $9.5 \%$ or 5.4 million children in the United States had been diagnosed with ADHD. The American Academy of Pediatrics (2007) stated that around fourth grade, students with ADHD often begin to fall behind academically due to the shift from learning to read to reading to learn. The determination is unclear whether more children now have ADHD or more children are being diagnosed with ADHD. However, ADHD is one of the most common childhood conditions, and one that is usually noticed first by a teacher (American Academy of Pediatrics, 2007).

\section{School data}

For the purposes of this study, research occurred in a non-Title I elementary school in west Georgia. This school is located within a county of 64 schools, 35 of which are elementary. In 2010, ninety-three percent of school-aged children in this county attended public school. Enrollment at the research site was 466 for the 2009-2010 school year (Governor's Office of Student Achievement, 2010). The teacher-researcher in this study instructed a regular third-grade classroom with 20 students, including seven students diagnosed with ADHD.

For the 2009-2010 school year, 64.6\% of this school's third graders met or exceeded the standards on the CRCT, as compared to $59.3 \%$ in the district. Specifically, $96 \%$ of third graders met or exceeded the standard in Reading (Governor's Office of Student Achievement, 2010). However, "the federal No Child Left Behind Act requires that states establish performance 
goals for all schools, districts, and the state to ensure that all students reach 100\% proficiency on state assessments by 2014" (Georgia School Council Institute, 2004, para. 1).

In order to establish a baseline reading level, third-grade students in the teacher-researcher's classroom were given the Standardized Test for the Assessment of Reading (STAR) at the beginning of the 2011-2012 school year. The STAR Reading test is a computerized comprehension test which measured students' reading grade equivalence. According to the STAR Reading Diagnostic Report (2011), 58\% of the teacher-researcher's third-grade students were reading below grade level. Twelve of the 19 students (63\%) in the class fell at or below the 50th percentile on a national ranking. Only seven students scored greater than $50 \%$ of students nationally in the same grade.

\section{Addressing reading deficits}

In order to address deficits in reading at the research site, the School Improvement Plan included the previously mentioned No Child Left Behind Act of 2001. The first performance goal of NCLB states that by 2013-2014, all students will be proficient in mathematics and reading/language arts. This proficiency is measured by CRCT results. The School Improvement Plan also cited the purchase of Renaissance Place, a web-based software intended to enhance students' reading abilities.

\section{Review of the Literature}

Learning to read is an important skill taught in lower-elementary school. Students begin learning about reading through narrative story structures (Akhondi, Malayeri, \& Samad, 2011). This foundation provides the framework for how students approach narrative text structures when they enter school and begin reading themselves. As students progress through upper grades, there is a shift in the reason students read. In upper-elementary school and beyond, students read to gain information (Gardill \& Jitendra, 1999). Understanding the meaning of a text, or reading comprehension, is essential to a student's ability to remain successful in school.

Comprehension is a reading skill that begins developing prior to conventional reading and continues to develop over time. Children learn that books have meaning through early interactions with texts. Dooley (2010) reported that as children progress through emergent literacy phases, books begin to take on new meanings, and children begin to develop text concepts. These 
emergent literacy phases lead to the emergence of comprehension. Dooley pointed out that teachers can use this information about the early emergence of comprehension to develop high-quality reading instruction as early as preschool. Scharlach (2008) and Stricklin (2011) agreed that comprehension instruction is vital to becoming a proficient reader. However, this type of reading instruction is lacking in the classroom.

In order for students to successfully comprehend the text they are reading, they must have specific comprehension strategies at their disposals. Students benefit from direct and sequential instruction in order to learn how to comprehend a text (Coyne et al., 2009). Students must be able to apply comprehension strategies to various genres and use them independently. Coyne et al. (2009) addressed five direct instructional strategies that can be useful in helping students learn to comprehend and retain texts. These strategies are conspicuous strategies, mediated scaffolding, strategic integration, priming background knowledge, and judicious review. Through these strategies, students receive explicit comprehension instruction with various genres and are given repeated opportunities to apply and develop these skills. While Coyne et al. presented comprehension strategies in a more broad sense, Scharlach (2008) listed eight specific comprehension strategies that are essential for students. These strategies were: predicting and inferring, visualizing, making connections, questioning, determining main idea, summarizing, checking predictions, and making judgments. Stricklin (2011) suggested to teach students to use the "Fab Four": predict, clarify, question, and summarize. Scharlach and Stricklin agreed that comprehension must be explicitly taught and students must be actively engaged in reading in order for comprehension to occur.

In order to help students remain actively engaged while reading a text, Scharlach (2008) developed the START (Students and Teachers Actively Reading Texts) framework. Through the use of this framework, students learned to use specific strategies taught through teacher modeling and scaffolding and were released to use the strategies on their own when ready. This framework highlighted the use of recording sheets to help students stay focused and organized while reading text. The use of teacher modeling was also an essential component of this study. Coyne et al. (2009) agreed that modeling is at the heart of explicit instruction.

Students in this study recorded predictions, inferences, and other key points while reading. The use of the recording sheets kept students actively engaged in the text and also increased students' metacognitive use of comprehension strategies (Scharlach, 2008). The findings proved the im- 
portance of using recording sheets while reading and confirmed that it is not enough to simply teach comprehension strategies. Students must be actively engaged during the reading process in order to improve comprehension of the text.

Teachers can help students remain engaged in reading by providing them with structured reading activities through the use of graphic organizers. According to Jitendra and Gajria (2011), graphic organizers help students organize information and develop schema about that information. When schema is created, information is more easily retained and comprehension increases. Graphic organizers also help students to see the relationships among information or concepts in the text (Jitendra \& Gajria, 2011) and provide a visual framework for contextual information (Coyne et al., 2009). In completing graphic organizers, students become more familiar with common occurrences in texts. Proficient readers are prepared for these common occurrences and approach the text with a plan.

Akhondi et al. (2011) stated that readers who are unfamiliar with text structures are at a disadvantage because knowledge of text structure facilitates comprehension. Through text-structure knowledge and the use of graphic organizers, students are able to store information in their shortterm memories. When information is connected to prior knowledge, the students can retain that information in their long-term memories (Akhondi et al., 2011). With the use of graphic organizers, students become more familiar with text structure and the material becomes more meaningful and accessible to the students (Jitendra \& Gajria, 2011). The visual organization of information helps students decide what is most important in the text and comprehension increases.

One type of graphic organizer that can be helpful to students in organizing information is a story map. "Story maps provide a visual-spatial display for key information in narrative texts. These maps function to prompt learners to identify story elements and provide space for them to record this information" (Boulineau, Fore, Hagan-Burke, \& Burke, 2004, p. 106). Generally, story maps include elements, such as characters, time, problem, goal, action, and outcome (Jitendra \& Gajria, 2011; Stagliano \& Boon, 2009). This strategy can be used across many different age groups and ability levels. Coyne et al. (2011) stated that story maps for kindergarten students might include sections for recording the beginning, middle, and end of a story, while upper-grade maps might include more in-depth information, such as problem and resolution. Story maps can be used at various times before, 
during, and after reading. These maps not only help students with literal comprehension but also encourage inferential thinking (Jitendra \& Gajria, 2011).

\section{Student populations}

Gardill and Jitendra (1999) conducted a study with six middle-school students with learning disabilities. In this study, students read passages, completed story maps, and were assessed through comprehension tests. Results showed that all six students improved in comprehension during the study. A similar study was conducted by Babyak, Koorland, and Mathes (2000) with four upper-elementary students with behavioral disorders. In this study, the researchers taught the story elements of characters, settings, problems, events, and outcomes. Students read passages, retold the passages in their own words, completed story maps, and were assessed through comprehension tests. Results revealed that the number of correct responses on the comprehension tests increased throughout the study. Boulineau et al. (2004) implemented a study with six elementary-school students with learning disabilities in a series of three phases: baseline, intervention, and maintenance. Students were taught story elements in the first phase and completed story maps with assistance in the second phase. Students worked to complete story maps independently in the third phase. Results confirmed that not only did the percentage of correct story elements increase for each student but the students were also able to maintain the strategy on their own.

While Boulineau et al. (2004) studied the effects of story mapping on students in elementary and middle school, Stone, Boon, Fore, Bender, and Spencer (2008) examined the effects of text maps, as they are referred to in this study, on the reading comprehension of four high-school students with emotional and behavioral disorders. As the other studies have also confirmed, the results of this study proved an increase in comprehension scores through the use of story maps. However, although the students acknowledged that story maps helped them improve their understanding of texts, they also recognized that they were no more engaged in the text than they were before the intervention (Stone et al., 2008).

Stagliano and Boon (2009) added to this body of research by conducting a study to examine the effects of story mapping on the reading comprehension of students with learning disabilities. However, this study specifically focused on expository texts. Similar to Boulineau et al. (2004), the study 
was conducted in three phases: baseline, intervention, and maintenance. All three participants showed gains in correct comprehension question responses after completing the story maps and also demonstrated maintenance of the strategy in the final phase. The elementary students in this study stated that they enjoyed using the story mapping strategy and felt that it helped them to organize their thoughts about the texts. Wade, Boon, and Spencer (2010) continued the use of story maps with students with disabilities through the use of the computer software Kidspiration. The basis of this study was that computer-based instruction and story mapping have both proven to be effective means of instruction, so the combination of the two computer-based story mapping should be equally as effective. Students created story maps and studied those maps before comprehension tests were given. The results showed great gains in comprehension scores, with one student increasing from $22 \%$ to $85 \%$, another from $44 \%$ to $89 \%$, and the last from $33 \%$ to $85 \%$. All three students maintained the strategy with average comprehension scores of $81 \%$ or higher (Wade, Boon, \& Spencer, 2010). These studies confirmed that story mapping was an effective comprehension strategy when working with students with specific learning disabilities.

In several of the previously mentioned studies, the effect of story mapping on students with specific learning disabilities or behavioral disorders was examined. However, there are other student populations who also struggle with reading comprehension. Students with Autism Spectrum Disorder (ASD) can struggle with reading comprehension due to problems, such as hyperlexia. Hyperlexia is high word recognition accompanied by poor comprehension (Gately, 2008). Many times, students can decode and read the text fluently, but are unable to understand the meaning. Dooley (2010) suggested that comprehension is not simply conventional print reading. Comprehension is a process that requires the use of unconventional text cues, such as images, social interactions, and the layout of the print. Gately (2008) specified the use of story maps as one possible visual map for students with ASD, specifically when there are no pictures in a book. The use of story maps can be taught in the regular education classroom and will benefit many different student populations within the class, including students with specific learning disabilities and ASD.

While there is a substantial amount of research addressing the use of story maps with students with learning disabilities, research is lacking on the use of story maps to improve the reading comprehension of students with Attention Deficit Hyperactivity Disorder (ADHD). McConaughy, Volpe, Antshel, Gordon, and Eiraldi (2011) stated that students with ADHD often 
have significant weaknesses in the areas of reading and mathematics. DuPaul et al. (2006) pointed out that the achievement of students with ADHD in reading and mathematics is particularly important because these two subjects contain skills that will be needed by the students for the rest of their lives. "ADHD is associated with poor grades, lowered reading and math standardized test scores, higher grade retention, and increased rates of detention and expulsion which eventually result in lower rates of high school graduation and postsecondary education" (Bussing, Mason, Bell, Porter, \& Garvan, 2010, p. 595).

McConaughy et al. (2011) conducted a study to compare the differences in the academic performances and social behaviors of students with ADHD and those without. Standardized achievement tests and cognitive abilities tests scores were used to determine student performance, as well as parents and teacher rating scales. Students with ADHD showed significant academic impairments on six different measures of academic performance compared to other students without ADHD. Based on the differences between predicted achievement test scores and actual test scores, $34 \%$ of students with ADHD in the sample were estimated to have learning disabilities and $25 \%$ showed skill deficits in reading and language (McConaughy et al., 2011). In relation to the reading and language deficits, a study was conducted by DuPaul et al. (2006) to examine two consultation models implemented with first through fourth graders diagnosed with ADHD. In one model, teachers were given resources and strategies by consultants to use with the students with ADHD. In the second model, data was collected based on each student's strengths and weaknesses, and interventions were tailored to student's particular needs. Although there was no significant difference in tests scores between the two groups, this research supported the idea of direct and explicit reading instruction, and students in the study showed great gains in reading fluency.

McConaughy et al. (2011) and DuPaul et al. (2006) both agreed that students with ADHD who struggle academically need specific, targeted interventions, as well as interventions to reduce the core symptoms of ADHD. These core symptoms include low productivity, poor completion of assignments, and not paying attention to instruction (McConaughy et al., 2011). DuPaul et al. pointed out that the method of intervention, whether teacher-driven or data-driven, did not have a significant effect. However, the interventions must be directly related to student weaknesses. McConaughy et al. stated that "by virtue of their diagnosis, children with ADHD can be considered at risk for more severe problems later on" (p. 222). 


\section{Limitations}

A significant amount of research has been conducted in the area of reading instruction. The majority of this research has focused on the development of the alphabetic principle and phonological awareness. However, much less research has been published in the area of reading comprehension. Many of the studies that have been conducted in the area of reading comprehension have focused on students with learning disabilities or behavioral disorders (Babyak et al., 2000; Boulineau et al., 2004; Gardill \& Jitendra, 1999; Jitendra \& Gajria, 2011; Stagliano \& Boon, 2009; Stone et al., 2008; Wade et al., 2010). Research has shown that students with ADHD often struggle with reading as well (DuPaul et al., 2006; McConaughy et al., 2011).

\section{Purpose of Study}

The purpose of this study was to examine the effects of one specific comprehension strategy, story mapping, on the reading comprehension scores, on-task behaviors, and attitudes of third-grade students with ADHD. Students with ADHD who have academic deficiencies need direct and explicit instruction combined with targeted interventions. These interventions must not only meet their academic needs, but must also help to combat the core symptoms of ADHD, such as off-task behavior, that negatively impact academic performance.

This study added to the body of research that is currently available on reading strategies to improve comprehension. Research that addresses reading deficits and targeted instruction to improve comprehension is beneficial to both third-grade teachers and students. Since researchers agree that direct and explicit instruction are imperative in improving comprehension (Scharlach, 2008; Stricklin, 2011) and students with ADHD need targeted instruction to reduce the core symptoms of ADHD (McConaughy et al., 2011; DuPaul et al., 2006), the aim of this research was to provide thirdgrade teachers of students with ADHD evidence to support story mapping as a successful approach to teaching comprehension.

\section{Research Questions}

Research question 1 . Will story mapping increase the reading comprehension scores of students with ADHD when compared to reading comprehension scores prior to story mapping? 
Research question 2. During the story mapping intervention, will students with ADHD show an increase in on-task behavior?

Research question 3. During the story mapping intervention, will there be an increase in positive attitudes toward reading and the intervention?

\section{Definition of Variables}

\section{Story mapping}

Story mapping was the student use of a teacher-created graphic organizer containing areas for students to record information about various story elements such as characters, setting, problem or events, and conclusion.

\section{Reading-comprehension scores}

Reading-comprehension scores referred to the percentage correct on a series of comprehension tests based on stories from the basal reader.

\section{On-task behavior}

On-task behavior was measured by a Likert-type scale included as a part of the researcher's fieldnotes. The teacher-researcher responded to the statement, "Student exhibited on-task behavior during the intervention process" by choosing a number on the scale. The scale ranged from 5 (strongly agree) to 1 (strongly disagree). Students were considered on task if they were engaged and actively participated in story mapping.

\section{Attitudes}

Students' attitudes were measured through a review of the researcher's fieldnotes and are defined as the feelings of students regarding the use of story mapping. The teacher-researcher marked positive, indifferent, or negative to reflect students' attitudes during the intervention period that day.

\section{Methods}

\section{Setting and participants}

The participants in this study $(N=6)$ were third-grade students enrolled in a public elementary school in west Georgia. Of the 466 students enrolled 
during the 2009-2010 school year, 39\% were Black, 45\% were White, 2\% were Asian, and 13\% were Multiracial. Students who were eligible for free or reduced lunch made up 59\% of the student population, compared to the state average of $56 \%$. Students receiving special education services made up 19\% of the student population (Governor's Office of Student Achievement, 2010).

The six students in this study had been diagnosed with ADHD by a physician and were all taking medication for the symptoms of ADHD during the study. Participants were in the teacher-researcher's class for the 2011-2012 school year and were selected through convenience sampling. All participants were 8 years old at the time of the study. Table 1 shows the demographic data of the student participants. The teacher-researcher was the only adult participant.

Table 1

Student Demographics

\begin{tabular}{lccc}
\hline \multicolumn{4}{c}{ Ethnic Group } \\
\hline Gender & Black & White & Multiracial \\
\hline Male & 1 & 1 & 1 \\
Female & 1 & 2 & 0 \\
\hline
\end{tabular}

Based on the STAR Reading Diagnostic Report (2011), three of the six students (50\%) with ADHD scored below grade level in reading comprehension at the beginning of the 2011-2012 school year. Suggestions from this report included guiding the students' reading practice through the use of the Accelerated Reader program. Accelerated Reader is a computerized progressmonitoring tool through which students take comprehension tests on the books they read. Teachers and parents can monitor tests taken, as well as levels of books and comprehension tests scores. The STAR Reading Diagnostic Report (2011) indicated that students should score $85 \%$ or higher on comprehension tests in order to have continued growth in reading. According to the Accelerated Reader Diagnostic Report (2011), four of the six participants (67\%) had reading comprehension averages below $75 \%$ at the end of the first 9 weeks. Three of those four participants had averages lower than $70 \%$.

\section{Intervention}

The teacher-researcher began the study at the beginning of the second semester. The study was explained to the six participants and parental and student consents were obtained. Each participant completed the STAR 
Reading test to provide baseline data. Four reading comprehension tests scores from the end of the first semester were also obtained and recorded by the teacher-researcher to use in comparison with tests scores after the implementation of the intervention. All participants in the study had the same teacher, basal reader, type of instruction, and assessments.

In order to increase reading comprehension, on-task behavior, and positive attitudes toward reading, the comprehension strategy of story mapping was introduced to the participants. Although the participants have used different types of graphic organizers such as Venn diagrams and thinking maps, the teacher-researcher had not used story mapping with the participants prior to the study. The teacher-researcher emphasized to the participants that story maps provide a way for them to break apart the information in a story in order to remember the information more clearly when they are trying to retell the story or answer questions about the story. The story maps were teacher-created, and the same story map format was used throughout the intervention period. Elements of the story map included title, author, characters, setting, story events, and conclusion.

The intervention period was 5 weeks long. Using stories from the McMillan/McGraw Hill basal reader, the teacher-researcher chose four stories, one story per week, to use with the participants. An additional story was chosen to use as a model story. During the first week of the intervention period, the teacher-researcher modeled the use of the story map with the students using a dry-erase board. For the remaining 4 weeks of intervention, students worked independently to record the elements of the story on the story map.

Each week of the intervention period, the teacher-researcher used a 5 day reading routine. If any participant was absent or missed the daily routine, that student worked with the teacher-researcher to make up that day's activities before moving on. On day 1, students heard the stories read aloud by the teacher-researcher. The students listened to the stories on CD and followed along using reading highlight strips on day 2 and took turns reading the stories aloud on day 3. During these days, the teacher-researcher reviewed the elements of the story with the participants and asked questions in order to guide students in identifying each element of the story. Story maps were completed on day 3 after students read the story aloud. The group of participants then discussed each element, and the teacher-researcher guided students in correcting any mistakes made in completing the story map. Students read the story aloud with a partner from the participant group on day 4. After reading, 
students reviewed the story map, quizzing each other on the elements of the story. The teacher-researcher moved among the groups to listen to students read and monitor the review of the story map. On day 5, students reviewed their story maps individually before the comprehension tests. Each participant then completed the AR story test and the story comprehension test from the MacMillan/McGraw Hill reading series. The teacher-researcher recorded each participant's scores for comparison with scores prior to the intervention.

In order to assess growth and progress, the participants completed the STAR Reading test at the end of the 5 weeks of intervention. The teacher-researcher also recorded fieldnotes each day of the intervention period. Fieldnotes were related to students' attitudes, on-task behavior, and other observations made during the completion of the story maps.

\section{Data collection techniques}

In order to determine the effects of story mapping on students' reading comprehension, on-task behavior, and positive attitudes toward reading, the teacher-researcher used several data collection instruments.

STAR Reading tests. As a pretest and posttest, all students completed the STAR Reading computerized comprehension assessment. Multiple tests conducted by Renaissance Learning (2011) have proven the validity and reliability of the STAR Reading test as an accurate measure of student comprehension. This test consisted of 25 multiple-choice items and took approximately 10 minutes per student. It is scored based on how students perform in comparison to norm groups of students nationally (Renaissance Learning, 2011). For the purposes of this study, the students' grade equivalencies were analyzed using descriptive statistics. A paired one-tailed t-test was also used to test for significance. Results were interpreted by comparing students' grade equivalencies before and after the intervention.

Story-comprehension tests. Comprehension tests from the MacMillan/ McGraw-Hill reading curriculum (2005) were given to measure each student's comprehension of the story. The tests were examined by three teacher-researchers in order to ensure content validity. Each test consisted of 10 multiple-choice questions. Tests were administered to all students before and after the intervention and were scored according to the percentage of questions answered correctly. Students' scores were analyzed using a paired one-tailed t-test. Results were interpreted by comparing tests scores before the intervention to tests scores after the intervention. 
Accelerated Reader (AR) tests. Comprehension tests from the computerized assessment program Accelerated Reader were used as an additional measure of each student's comprehension of the story. Accelerated Reader quizzes were proved to be valid through a controlled validity study (Renaissance Learning, 2009). Each test consisted of 10 multiple-choice questions and was scored based on the percentage of questions answered correctly. Tests were completed by all students before and after the intervention and were scored according to the percentage of questions answered correctly. Students' scores were analyzed using a paired one-tailed t-test. Results were interpreted by comparing tests scores before the intervention to tests scores after the intervention.

Fieldnotes. The teacher-researcher recorded fieldnotes related to the intervention process. In the study conducted by Scharlach (2008), anecdotal evidence reported by teachers was analyzed to determine the success of the START framework. Similarly, in the study conducted by Dooley (2010) fieldnotes were the main source of data collection. In this study, fieldnotes were recorded each day after school hours during the intervention period. The fieldnotes related to students' attitudes toward the intervention, ontask behavior, interactions with peers, and interactions with the teacherresearcher. The teacher-researcher designed the fieldnotes with Likert-type scales to rank students' attitudes, as well as levels of on-task behavior. Attitudes and on-task behavior were analyzed using paired one-tailed t-tests. Results were interpreted by examining scores for improvement throughout the intervention.

\section{Results}

The data collected in this study provided information to compare students' reading comprehension before and after the implementation of the story mapping intervention. Three data collection instruments were used to assess comprehension. The teacher-researcher also collected fieldnotes which were used to provide information about students' attitudes toward reading and on-task behavior during the intervention process.

At the beginning and end of the intervention period, students completed the STAR Reading test. This was a computerized comprehension test consisting of 25 items. Students were scored based on a comparison of how other students performed nationally. Means and standard deviations of students' pretest and posttest scores are shown in Table 2. 
Table 2

Comparison of Reading Levels

\begin{tabular}{lccccc}
\hline STAR Reading Test & $N$ & $M$ & $S D$ & $t$-value & $p$ \\
\hline Pretest & 6 & 3.87 & 1.53 & 0.21 & 0.42 \\
Posttest & 6 & 3.72 & 0.90 & & \\
\hline
\end{tabular}

Although three students' $(N=6)$ grade equivalency scores improved from pretest to posttest, the overall improvement of the students was not significant. The mean grade equivalency score on the posttest $(M=3.72$, $S D=0.90)$ was lower than that of the pretest $(M=3.87, S D=1.53)$. A t-test was conducted at the alpha level .05 to test for significance. Results revealed that story mapping did not significantly affect students' reading levels.

The teacher-researcher computed Cohen's d to reveal the practical significance in the difference in scores on the pretest and posttest. On average, after participating in the intervention, students would perform higher than $54 \%$ of students who did not participate in the intervention. Results from the STAR Reading test showed that the intervention had a negligible effect $(d=0.13)$ on students' reading grade equivalencies.

At the end of each week of intervention, students completed a story-comprehension test from the McMillan/McGraw Hill reading series. These tests correlated with the stories students mapped during the intervention period that week. The teacher-researcher obtained scores from four comprehension tests prior to the intervention period and four scores during the intervention period. Tests consisted of 10-multiple choice questions related to the weekly story. Means and standard deviations for these tests are shown in Table 3.

Table 3

Comparison of McMillan/McGraw Hill Comprehension Scores

\begin{tabular}{llcccc}
\hline Students' Test Averages & $N$ & $M$ & $S D$ & $t$-value & $p$ \\
\hline Before Story Mapping & 6 & 73.33 & 18.21 & -2.27 & .06 \\
With Story Mapping & 6 & 85.42 & 5.10 & & \\
\hline
\end{tabular}

Students' test averages improved with the story mapping strategy revealing a $12.09 \%$ mean increase. However, although students' test averages were higher $(M=85.42, S D=5.10)$ during the story mapping intervention period, the difference was not significantly higher than before the strategy was implemented. Story mapping did not have a statistically significant ef- 
fect on students' comprehension scores on tests from the McMillan/McGraw Hill Reading Series.

Figure 1 is also related to the McMillan/McGraw Hill reading comprehension test scores. Tests $1,2,3$, and 4 were taken prior to the story mapping intervention. Tests $5,6,7$, and 8 were taken during the intervention period.

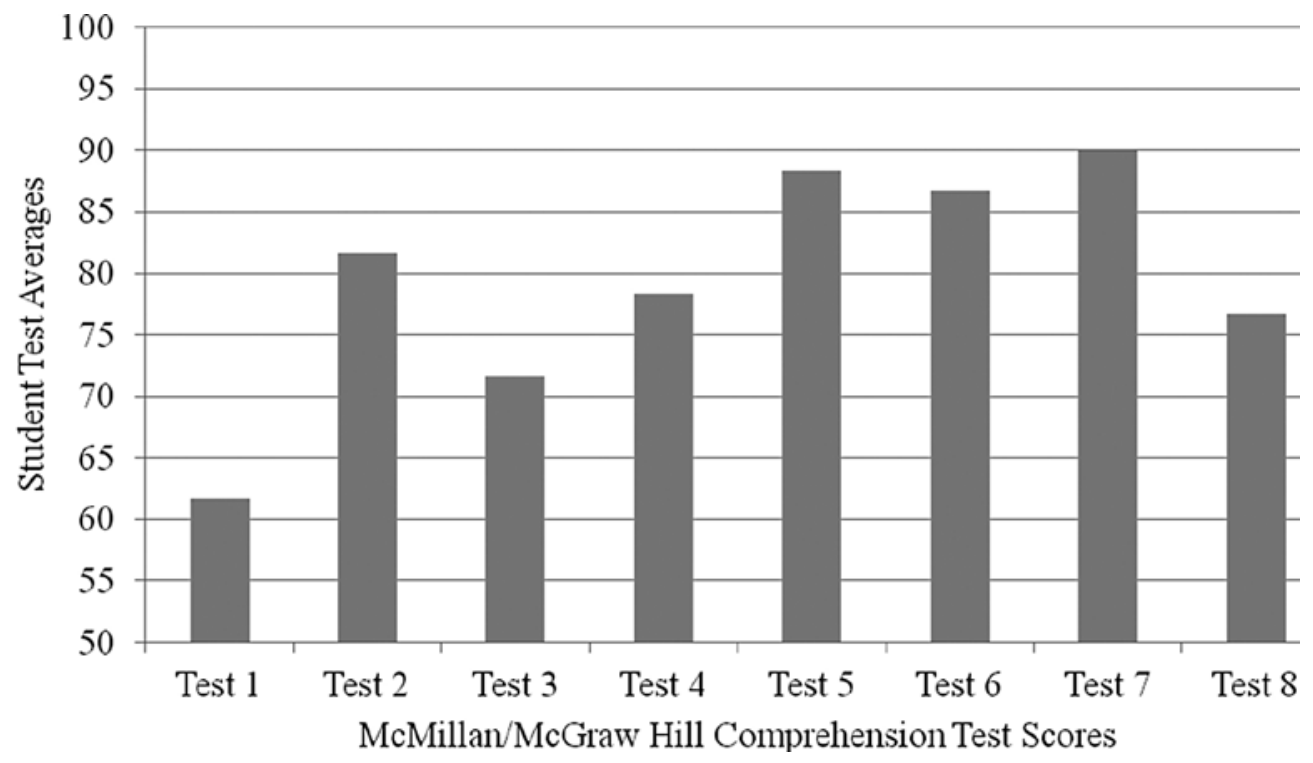

Figure 1. Comparison of Student Averages on Reading Comprehension Tests.

On Test 1 , students $(N=6)$ had an average score of $61.67 \%(S D=33.71)$. Students averaged $81.67 \%(S D=18.35)$ on Test 2 and $71.67 \%(S D=14.72)$ on Test 3. On Test 4, students had an average score of $78.33 \%(S D=30.61)$. Students averaged $88.33 \%(S D=7.53)$ on Test $5,86.67 \%(S D=12.11)$ on Test $6,90.00 \%$ on Test $7(S D=10.95)$, and $76.67 \%$ on Test $8(S D=13.66)$.

As shown in Figure 1, students' scoring became more consistent during Tests 5, 6, and 7 with the story mapping intervention. The standard deviation decreased from 18.21 before the intervention to 5.10 during the intervention. Students scored highest on Test 7 which was during the intervention period. Only one score fell below 70\% while students were using story maps.

The t-test revealed no statistically significant difference in scores before and during the intervention period. Therefore, the teacher-researcher calculated Cohen's d to reveal the practical difference in scores. On average, 
students who participated in the story mapping intervention would score higher than $84 \%$ of students who did not participate in the intervention. These results revealed that the story mapping intervention had a large effect $(d=0.99)$. Students who participated in the intervention showed a medium increase of $16 \%$ in scores on the McMillan/McGraw Hill comprehension tests.

Table 4

Comparison of Accelerated Reader Comprehension Scores

\begin{tabular}{lccccc}
\hline Class Scores & $N$ & $M$ & $S D$ & $t$-value & $p$ \\
\hline Before Story Mapping & 6 & 70.42 & 14.78 & -1.57 & 0.17 \\
With Story Mapping & 6 & 84.58 & 12.79 & & \\
\hline
\end{tabular}

Means and standard deviations are given in Table 4 for the average of students' Accelerated Reader (AR) comprehension scores before the story mapping strategy and during the use of story maps. The mean score $(M=84.58, S D=12.79)$ of tests while using the story mapping strategy was not significantly higher than the mean score $(M=70.42, S D=14.78)$ of AR tests prior to the use of story mapping. A t-test conducted at the alpha level .05 revealed that students' comprehension test scores using the AR program did not significantly improve after implementing the story mapping strategy.

The calculation of Cohen's d showed that story mapping had a very large effect on students' AR scores $(d=1.12)$. On average, students who participated in the intervention would score higher on AR tests than $86 \%$ of students who did not participate in the intervention. Results revealed a medium increase of $20 \%$ in AR comprehension scores of students who participated in story mapping.

During this study, the teacher-researcher recorded fieldnotes each day of intervention. Fieldnotes related to on-task behavior, students' attitudes about reading and the intervention itself, and other observations made by the teacher-researcher. The teacher-researcher analyzed the fieldnotes for improvements in on-task behavior and attitudes toward reading during the time students participated in story mapping. 
Table 5

Students' On-Task Behavior During Intervention Period

Students exhibited on-task behavior during the intervention process.

\begin{tabular}{lccccc}
\hline $\begin{array}{l}\text { Intervention } \\
\text { Period }\end{array}$ & $\begin{array}{c}5 \\
\text { (Strongly } \\
\text { Agree) }\end{array}$ & $\begin{array}{c}4 \\
\text { (Agree) }\end{array}$ & $\begin{array}{c}3 \\
\text { (Neutral) }\end{array}$ & $\begin{array}{c}2 \\
\text { (Disagree) }\end{array}$ & $\begin{array}{c}1 \\
\text { (Strongly } \\
\text { Disagree) }\end{array}$ \\
\hline Week 1 & $53.33 \%$ & $40.00 \%$ & $6.67 \%$ & $0.00 \%$ & $0.00 \%$ \\
\hline Week 2 & $20.00 \%$ & $40.00 \%$ & $30.00 \%$ & $10.00 \%$ & $0.00 \%$ \\
\hline Week 3 & $36.67 \%$ & $40.00 \%$ & $16.67 \%$ & $6.67 \%$ & $0.00 \%$ \\
Week 4 & $33.33 \%$ & $41.67 \%$ & $12.50 \%$ & $12.50 \%$ & $0.00 \%$ \\
Week 5 & $54.17 \%$ & $37.50 \%$ & $4.17 \%$ & $4.17 \%$ & $0.00 \%$ \\
\hline
\end{tabular}

During the intervention period, the teacher-researcher recorded students' levels of on-task behavior through a Likert-type scale. The fieldnotes were analyzed to assess whether or not students' behavior improved while using story mapping. Results were compiled for each week of intervention and are reported in Table 5.

The teacher-researcher recorded that students exhibited on-task behavior during Week 1 93.33\% of the time, receiving a 4 (Agree) or 5 (Strongly Agree). Students were on-task $60.00 \%$ of the time in Week 2, 76.67\% in Week 3, $75.00 \%$ in Week 4 , and $91.67 \%$ in Week 5 . In Week 3, 30.00\% of the time, students were rated 3 (Neutral) where behaviors were on and off-task during the intervention period. The teacher-researcher found no off-task behaviors in Week 1. However, off-task behaviors surfaced in Week 2 with students recorded off-task $10.00 \%$ of the time. Off-task behaviors during the remainder of the intervention period were $6.67 \%$ in Week $3,12.50 \%$ in Week 4 , and $4.17 \%$ in Week 5 . There was no record of students receiving the rating of 1 (Strongly Disagree) at any time during the intervention period.

Table 6

Students' Attitudes Toward Reading and Story Mapping

\begin{tabular}{lccc}
\hline Intervention Period & Positive & Indifferent & Negative \\
\hline Week 1 & $93.33 \%$ & $6.67 \%$ & $0.00 \%$ \\
Week 2 & $63.33 \%$ & $26.67 \%$ & $10.00 \%$ \\
Week 3 & $80.00 \%$ & $13.33 \%$ & $6.67 \%$ \\
Week 4 & $83.33 \%$ & $16.67 \%$ & $0.00 \%$ \\
Week 5 & $91.67 \%$ & $8.33 \%$ & $4.17 \%$ \\
\hline
\end{tabular}


The teacher-researcher also recorded students' attitudes toward reading and the intervention process. Weekly percentages are shown in Table 6. On average, students exhibited positive attitudes $82.33 \%$ of the time during the story mapping intervention. The highest percentage of positive attitudes occurred during Week 1 (91.67\%). This was followed by the lowest percentage of positive attitudes (63.33\%) during Week 2. Also in Week 2, the highest percentage of negative attitudes was recorded at $10.00 \%$. However, throughout the remainder of the intervention period, students' positive attitudes increased.

The teacher-researcher analyzed the remaining fieldnote observations for themes in students' responses, both verbal and non-verbal, to the intervention process. Notes were also recorded related to two students' not taking prescribed ADHD medication during several days of the intervention period. Students made many positive comments related to participating in a small group. Two students asked to continue the small group throughout the year, and one student asked to bring a friend to the group. Students also made positive comments about the use of reading highlight strips on Day 2 of each intervention week. Many references were made related to story elements during student discussions. As the days of intervention passed, students were able to more quickly identify story elements, as well as ask and answer questions related to the story. The only negative comments recorded by the teacherresearcher were related to students wanting to rush through the intervention period and students having difficulties working with partners on Day 4 of the intervention week. Overall, student comments about the intervention were positive, and student comments reflected engagement and learning.

\section{Discussion}

\section{Conclusions}

In order to determine the effects of story mapping on students with ADHD, the teacher-researcher compared students' reading comprehension scores on achievement measures before and during the story mapping intervention. On-task behaviors during the intervention, as well as students' attitudes toward reading and the intervention were recorded by the teacher-researcher in the form of fieldnotes. Students also participated in a pre and posttest to assess reading grade equivalencies before and after the intervention period.

Will story mapping increase the reading comprehension scores of students with ADHD when compared to reading comprehension scores prior to story mapping? Although three of six $(50 \%)$ students' grade equivalen- 
cies increased, the STAR Reading test did not reveal significant improvement in reading comprehension from pretest $(M=3.87, S D=1.53)$ to posttest $(M=3.72, S D=0.90)$. However, the teacher-researcher used two other achievement measures to reveal whether or not story mapping increased the reading comprehension scores of students with ADHD when compared to reading comprehension scores prior to story mapping. Comprehension tests from the McMillan/McGraw Hill reading series and the Accelerated Reader (AR) program were used weekly to assess students' comprehension of the story.

The McMillan/McGraw Hill tests and AR tests showed no statistically significant difference in comprehension scores before and during the story mapping intervention. Computing the practical significance of the difference in scores through the use of Cohen's d proved otherwise. Students gained an average of $16 \%$ in comprehension scores on the McMillan/McGraw Hill tests showing that story mapping had a large effect $(d=0.99)$. The decrease in standard deviation from before the intervention $(S D=18.21)$ to during the intervention $(S D=5.10)$ supported this large effect with more consistent student scoring. Similarly, students improved AR comprehension scores by $20 \%$ during the intervention period showing that story mapping had a very large effect $(d=1.12)$. The data collected revealed an increase in students' comprehension scores as a result of the story mapping intervention. These findings are consistent with the research of Gardill and Jitendra (1999) and Babyak, Koorland, and Mathes (2000). However, while this research is focused on third-grade students with ADHD, Gardill and Jitendra worked with middle-school students, and Babyak, Koorland, and Mathes focused on upper elementary students with behavioral disorders.

During the story mapping intervention, will students with ADHD show an increase in on-task behavior? Throughout the intervention period, the teacher-researcher recorded fieldnotes related to students' levels of on-task behavior. Each day, students received a rating to correspond with the statement, "Student exhibited on-task behavior during the intervention process." Results showed the highest percentage of on-task behavior occurring during Week $1(93.33 \%)$. Through an analysis of the observational fieldnotes, the teacher-researcher concluded that this high percentage was due to the students' excitement about participating in the intervention as a small group. Based on the research of Coyne et al. (2009) which highlighted the importance of explicit modeling, the teacher-researcher also spent Week 1 modeling the story mapping strategy. Students were not required to create their own story maps during this period, which may have also led to higher percentages of on-task behavior. 
Although on-task behavior was lowest in Week 2 (60.00\%), on-task behavior increased in Week 3 and remained at $75 \%$ or higher for the remainder of the intervention period. Results did not show steady growth in on-task behavior while story mapping. However, the level of on-task behavior was considerably higher than off-task behavior during the intervention period. No student was given the rating of 1 (Strongly Disagree) at any time during the intervention. The results of this study supported research conducted by Scharlach (2008) revealing the positive connection between active engagement while reading a text and comprehension. These studies differ in that Scharlach used recording sheets where students recorded reactions from the texts, and this study focused solely on the identification of story elements through the use of story maps.

During the story mapping intervention, will there be an increase in positive attitudes toward reading and the intervention? Students' attitudes toward reading and the intervention were recorded daily as positive, indifferent, or negative. In research conducted by Stagliano and Boon (2009), students stated that they enjoyed using story maps and felt that they helped them organize their thoughts about a text. This study also revealed positive attitudes toward the use of story maps. Students were positive $82.33 \%$ of the time during the intervention period. The highest percentage of positive attitudes was recorded during Week 1 (93.33\%). The teacher-researcher concluded that students were excited about being selected to participate in the intervention process and high levels of positive attitudes were the result. The lowest percentage of positive attitudes was recorded in Week 2 (63.33\%). This was most likely due to the fact that Week 1 was a week of modeling. Students began using the story mapping strategy in Week 2. Results showed that positive attitudes did increase weekly from Week 2 to Week 5 when students were using the story mapping strategy independently. Through an analysis of the observational fieldnotes, records of negative attitudes were generally related to disagreements on Day 4 when working with a partner, as well as changes in a student's medication.

\section{Significance/impact on student learning}

Students with ADHD often struggle with reading. Previous research has shown that students with ADHD who struggle academically need specific, targeted interventions, as well as interventions to reduce the core symptoms of ADHD, such as off-task behavior (DuPaul et al., 2006; McConaughy et al., 2011). Additionally, Scharlach (2008) and Stricklin (2011) agreed that direct and explicit instruction is imperative to improving comprehension. This aim 
of this study was to provide targeted and explicit reading instruction while requiring the active engagement of students with ADHD through the use of a story map.

Although students' reading grade equivalencies did not show significant improvement as a result of this study, students' comprehension of the weekly stories did increase. The comparison of comprehension scores before and during the intervention was not statistically significant. However, data revealed a $12.09 \%$ mean increase in students' comprehension on the McMillan/McGraw Hill tests and a 14.16\% mean increase in students' AR comprehension scores as a result of the story mapping intervention. The practical significance in the difference of scores on these two achievement measures revealed that students participating in the story mapping intervention would score higher on average than $84 \%$ of students on the McMillan/McGraw Hill tests and $86 \%$ of students on the AR comprehension tests who did not participate in story mapping.

Findings in this study also showed that students exhibited on and offtask behaviors during the intervention an average of $14.00 \%$ of the time. However, students were on-task an average of $79.33 \%$ of the time during the intervention period and only exhibited an average of $6.67 \%$ of off-task behaviors. On average, students demonstrated positive attitudes $82.33 \%$ of the time while story mapping. Therefore, students with ADHD benefited from the story mapping intervention resulting in comprehension score gains, higher levels of on-task behavior, and increased positive attitudes.

\section{Factors influencing implementation}

The implementation of this study was affected with winter break falling during the last two weeks of the intervention period. During Weeks 4 and 5, Days 4 and 5 of the intervention were completed on Day 4 . This meant that students completed the partner reading activity, review of the story map, and two comprehension tests all in the same day. While students did not seem outwardly affected by these changes, students may have performed better on tests without such a lengthy intervention period.

\section{Limitations and implications}

Although story mapping has proven to be an effective tool in improving reading comprehension, there are several limitations in the design of this study that must be addressed. The study took place over a 5-week period, 
beginning with 1 week of modeling and 4 weeks of students completing story maps individually. Results may have been affected by this short period of time. It would be more beneficial to conduct this study over a longer period so that student growth can be better assessed. It would also be helpful to be able to include other achievement data, such as results of the Criterion Referenced Competency Test which were unavailable during the time period of this study.

This study examined the effects of story mapping on all students in one third-grade class with ADHD. This study could also be replicated with specific ADHD students who have been identified as having a specific weakness in reading. Results would be more reliable in showing the true effects of story mapping when only students who struggle with reading are involved and the intervention period is extended. Additionally, to increase the reliability of the results in this study, this research should be implemented in several classrooms in the same grade level. Students with ADHD should be assessed to identify struggling readers using the same assessment, such as the STAR Reading test. The intervention should be implemented with these students by teachers other than the teacher-researcher to remove researcher bias. Future researchers should also consider examining the effects of story mapping on specific subgroups of students with ADHD, such as boys compared to girls. Research should continue on how best to instruct students with ADHD and specifically how to remediate academic deficiencies effectively among these students.

The implications of this study are important because of the high percentage of children in the United States who have been diagnosed with ADHD and the percentage of those children who may struggle with reading. Story mapping is an effective strategy to use not only with students with ADHD, but with all students to promote active engagement while reading a text and better recall after reading. Specifically, the teachers and administrators can now implement this strategy with all students to increase reading comprehension. Reading instruction that includes explicit modeling, the breaking apart of stories element by element, and continual review of those elements will be effective. The ultimate goal is that students are eventually able to mentally break apart a story without the need for a handwritten story map.

Globally, teachers, administration, students and parents will benefit from the findings of this research by sharing the results with other teachers, colleagues, and families with similar learning and teaching needs in the classroom or at home. The story map template was added to a group of reading 
resources contained on a computer share drive at the research site but is open for national and international access. Teachers and parents have access to the template. Results were also shared with student teachers at the research site in order to deepen their knowledge about successful reading instruction and demonstrate the importance of students remaining actively engaged while reading a text.

\section{References}

Accelerated Reader Diagnostic Report (2011) [Computer software]. Wisconsin Rapids, WI: Renaissance Learning.

Akhondi, M., Malayeri, F., \& Samad, A. (2011). How to teach expository text structure to facilitate reading comprehension. Reading Teacher, 64(5), 368-372.

American Academy of Pediatrics. (2007). Understanding ADHD: Information for parents about Attention-Deficit/Hyperactivity Disorder. Retrieved from http://www.healthychildren. org/English/health-issues/conditions/adhd/Pages/ADHD-Basics.aspx

Babyak, A. E., Koorland, M., \& Mathes, P. G. (2000). The effects of story mapping instruction on the reading comprehension of students with behavioral disorders. Behavioral Disorders, 25(3), 239-258.

Boulineau, T., Fore, C., Hagan-Burke, S., \& Burke, M. D. (2004). Use of story-mapping to increase the story-grammar text comprehension of elementary students with learning disabilities. Learning Disability Quarterly, 27(2), 105-121.

Bussing, R., Mason, D., Bell, L., Porter, P., \& Garvan, C. (2010). Adolescent outcomes of childhood Attention-Deficit/Hyperactivity Disorder in a diverse community sample. Journal of the American Academy of Child and Adolescent Psychiatry, 49(6), 595-605. Centers for Disease Control and Prevention. (2010). Attention-Deficit/Hyperactivity Disorder (ADHD). Retrieved from http://www.cdc.gov/ncbddd/adhd/data.html

Coyne, M. D., Zipoli, R. R., Chard, D. J., Faggella-Luby, M., Ruby, M., Santoro, L. E., \& Baker, S. (2009). Direct instruction of comprehension: Instructional examples from intervention research on listening and reading comprehension. Reading \& Writing Quarterly, 25(2-3), 221-245.

Daggett, W. R., \& Hasselbring, T. S. (2007). What we know about adolescent reading. Retrieved from The International Center for Leadership in Education: http://www. leadered.com/pdf/Adolescent\%20Reading\%20Whitepaper.pdf

Dooley, C. (2010). Young children's approaches to books: The emergence of comprehension. Reading Teacher, 64(2), 120-130.

DuPaul, G. J., Jitendra, A. K., Volpe, R. J., Tresco, K. E., Lutz, J. G., Vile Junod, R.,E., Cleary, K.S. (2006). Consultation-based academic interventions for children with ADHD: Effects on reading and mathematics achievement. Journal of Abnormal Child Psychology, 34(5), 635-648.

Gardill, M. C., \& Jitendra, A. K. (1999). Advanced story map instruction: Effects on the reading comprehension of students with learning disabilities. The Journal of Special Education, 33(1), 2-28.

Gately, S. E. (2008). Facilitating reading comprehension for students on the autism spectrum. Teaching Exceptional Children, 40(3), 40-45. 
Georgia School Council Institute. (2004). Adequate yearly progress (AYP). Retrieved from http:/ /www.gsci.org/topics/handouts/Adequate-Yearly-Progress.pdf

Governor's Office of Student Achievement. (2010). 2009-2010 Report Card. Retrieved from http: / /gaosa.org/ Report.aspx

Hernandez, D. J. (2011). Double jeopardy: How third-grade reading skills and poverty influence high school graduation. Retrieved from The Annie E. Casey Foundation: http://www.aecf.org/ /media/Pubs/Topics/Education/Other /DoubleJeopardyHowThirdGradeReadingSkillsandPovery / DoubleJeopardyReport040511FINAL.pdf Jitendra, A. K., \& Gajria, M. (2011). Reading comprehension instruction for students with learning disabilities. Focus on Exceptional Children, 43(8), 1-16.

Lesnick, J., Goerge, R. M., Smithgall, C., \& Gwynne, J. (2010). Reading on grade level in third grade: How is it related to high school performance and college enrollment? Retrieved from The Annie E. Casey Foundation: http://www.aecf.org/ /media/Pubs /Topics/Education/Early\%20Childhood\%20and\%20School\%20Readiness / ReadingonGradeLevelinThirdGradeHowisitRelatedtoHighSchoolPerformance /Reading\%20 on\%20Grade\%20Level_Casey_REVISIONS_2010\%2010\%201\%20\%201.PDF

Lyon, G. R. (1999). Statement on local school districts and individual schools at the hearing on Title I (education of the disadvantaged) of the Elementary and Secondary Education Act. Presented before the House Committee on Education and the Workforce. Retrieved from http://www.hhs.gov/asl/testify/t990727a.html

McConaughy, S. H., Volpe, R. J., Antshel, K. M., Gordon, M., \& Eiraldi, R. B. (2011). Academic and social impairments of elementary school children with Attention Deficit Hyperactivity Disorder. School Psychology Review, 40(2), 200-225.

Renaissance Learning. (2009). Accelerated Reader. Understanding reliability and validity. Retrieved from http://research.renlearn.com/research/pdfs/212.pdf

Renaissance Learning. (2009). STAR Reading. Understanding reliability and validity. Retrieved from https://hosted203.renlearn.com/57945/Shared/Resources/SR / SRRPReliabilityValidity.pdf

Renaissance Learning (2011). High quality test items ensure reliability and validity. Retrieved from http://www.renlearn.com/sr/overview/sample.aspx

Scharlach, T. (2008). START comprehending: Students and teachers actively reading text. Reading Teacher, 62(1), 20-31.

Stagliano, C., \& Boon, R. T. (2009). The effects of a story-mapping procedure to improve the comprehension skills of expository text passages for elementary students with learning disabilities. Learning Disabilities-A Contemporary Journal, 7(2), 35-58. STAR Diagnostic Report (2011) [Computer software]. Wisconsin Rapids, WI: Renaissance Learning.

Stone, R. H., Boon, R. T., Fore III, C., Bender, W. N., \& Spencer, V. G. (2008). Use of text maps to improve the reading comprehension skills among students in high school with emotional and behavioral disorders. Behavioral Disorders, 33(2), 87-98. Stricklin, K. (2011). Hands-on reciprocal teaching: A comprehension technique. Reading Teacher, 64(8), 620-625.

The Annie E. Casey Foundation. (2010). Success starts with reading [News release]. Retrieved from http://www.aecf.org/Newsroom/NewsReleases/HTML/2010Releases/ /media /PDFFiles/Newsroom/FINAL\%20RELEASE\%20\%20\%20\%20Success\%20Starts \%20with\%20Reading\%205\%2014NoEmbargo.pdf 
The McGraw-Hill Companies. (2005). Reading. Desoto, Texas: MacMillan/McGraw Hill. U.S. Department of Education, Office of Special Education and Rehabilitative Services, Office of Special Education Programs. (2004). Teaching children with Attention Deficit Hyperactivity Disorder: Instructional strategies and practices. Retrieved from http://www2.ed.gov/rschstat/research/pubs/adhd/adhd-teaching-2006.pdf Wade, E., Boon, R. T., \& Spencer, V. G. (2010). Use of Kidspiration software to enhance the reading comprehension of story grammar components for elementary-age students with specific learning disabilities. Learning Disabilities-A Contemporary Journal, 8(2), 31-41.

\section{Authors}

Jaime N. Chavez, Ed. S.

Muscogee County Schools

Georgia

USA

James Martinez, Ph.D.

Valdosta State University

James L. and Dorothy H. Dewar College of Education

Department of Middle, Secondary, Reading, and Deaf Education

1500 North Patterson Street

Valdosta

GA 31698

USA

Email: jammartinez@valdosta.edu

Rachel Sutz Pienta, Ph.D.

The Richard W. Riley College of Education and Leadership

Department of Teacher Leadership

Walden University

100 Washington Avenue South

Suite 900

Minneapolis

MN 55401

Email: rachel.pienta@waldenu.edu 